\title{
UK consumer reactions to organic certification logos
}

\author{
Catherine Gerrard $^{* 1}$, Meike Janssen ${ }^{\# 2}$, Laurence Smith ${ }^{* 3}$, Ulrich Hamm ${ }^{\# 4}$, Susanne Padel ${ }^{* 5}$ \\ *Organic Research Centre \\ Hamstead Marshall \\ Newbury \\ Berkshire \\ RG20 0HR \\ UK \\ $+44(0) 1488658298$ \\ +44(0)1488 658503 \\ catherine.g@organicresearchcentre.com \\ laurence.s@organicresearchcentre.com \\ susanne.p@organicresearchcentre.com \\ \#Department of Agricultural and Food Marketing, \\ Faculty of Organic Agricultural Sciences, \\ University of Kassel \\ Steinstrasse 19 \\ 37213 Witzenhausen \\ Germany \\ Phone +49 5542981285 \\ Fax +495542981286 \\ M.Janssen@uni-kassel.de \\ U.hamm@uni-kassel.de
}

1. Dr Catherine Gerrard is a data analyst at Organic Research Centre with a PhD in applied mathematics, masters in applied equine science and the ACA chartered accountancy qualification from the Institute of Chartered Accountants of England and Wales.

2. Meike Janssen has a Master of Arts degree in Policy Studies and a Diploma degree in Business and Economics. She is a research assistant at the Department of Agricultural and Food Marketing at the University of Kassel.

3. Laurence Smith is a sustainability researcher at the Organic Research Centre.

4. Prof Dr Ulrich Hamm is the Head of the Department of Agricultural and Food Marketing at the University of Kassel.

5. Dr Susanne Padel is the team leader of the socio-economic resource accounting group at the Organic Research Centre.

Archived at http://orgprints.org/22557 


\title{
UK consumer reactions to organic certification logos
}

\begin{abstract}
:
Purpose - This paper considers the question of whether UK consumers recognise and trust organic certification logos and whether the presence of these logos on a product increases consumer willingness to pay for that product.

Methodology/approach - To ascertain the reaction of UK consumers to organic certification logos commonly used in the UK, this study makes use of three methods: focus groups, a consumer survey and a willingness to pay experiment (choice experiment).

Findings - These three approaches reveal that UK consumers associate certain benefits with organic foods but are generally unaware of how the industry is regulated. With regards to trust of the logo, the standards they think underlie the logo and the inspection system that they think is associated with the logo, UK consumers rate the Soil Association and Organic Farmers and Growers logos more highly than the EU logo or products labelled with just the word "organic". They appear willing to pay a premium for the additional assurance that these two logos provide, suggesting that where they are recognised, certification logos are valued.

Originality - To the authors' knowledge, no previous studies exist on whether UK consumers recognise and trust different organic certification logos. These findings show that where such logos are recognised they can help to give some assurance to the UK consumer and this is reflected in a willingness to pay a premium for foods labelled with the Soil Association and Organic Farmers and Growers certification logos as opposed to no logo or the (less well known) EU logo.
\end{abstract}

Keywords: Organic food, Consumer perceptions, Certification logos

Classification: Research paper

\section{Section 1: Introduction}

The question of consumers' attitudes towards organic food in general and their recognition of and trust in organic logos is of great importance to the organic industry. Unlike some qualities of food "organic" is not a quality that consumers can verify for themselves without external 
assurance; it is a "credence good" (Yiridoe et al., 2005). Consumers rely on being told that a product is organic, and sales of organic products will only occur if the consumer associates organic food with benefits that they value and believes the claim that a particular product is organic.

Various logos are used to indicate that a particular product satisfies organic standards. As of July 2010, an EU logo has to be displayed on all products that are sold as organic in Europe. Before this date, displaying the EU logo was possible but not compulsory. Products sold as organic in Europe must satisfy the requirements of the EU regulations on organic production and labelling of organic products (EC No. 834/2007 and several implementing regulations). These regulations stipulate the minimum standards which must be complied with for food produced in the EU to be sold as organic. In the UK, as in many other EU countries, additional logos exist indicating that the product has been produced in compliance with private standards. These standards have existed for many years, for example, the Soil Association, Organic Food Federation, Organic Farmers and Growers (OF\&G) and others.

The EU logo (both the former, voluntary logo which was used in this study and the mandatory logo introduced in July 2010) indicates that a product complies with the EU regulations as mentioned above. The private organic standards ensure that producers comply with the EU regulations but may also require compliance with a stricter set of standards. For instance, the Soil Association logo indicates that the product complies with the Soil Association standards which are stricter than the EU regulations in 61 instances (Organic Rules, 2011) including more restrictive rules regarding animal feed, the requirement for a livestock health plan, and greater emphasis on the requirement to support the agro-ecosystem. The OF\&G standards, on the other hand, have very few differences from the EU regulations.

To use any of these private organic logos the producer will have undergone an additional process of inspection and certification. Thus, the logos can be perceived as providing an additional level of assurance to the consumers. This relies, however, on consumers being aware of these logos and being aware of what they imply with regards to the products they label. So far, little scientific evidence exists on UK consumers' perception of and willingness to pay for different organic logos. In an inventory study of market prices of organic products no significant price difference was found between items with different private organic logos (Janssen and Hamm, 2011b).

This paper focuses on the reaction of UK consumers to organic certification logos which are commonly used in the UK. This paper considers the question of whether UK consumers recognise and trust organic certification logos and whether the presence of these logos on a product increases consumer willingness to pay for that product. This is an important question for producers as they would require the costs of certification (in terms of both the direct costs and

Archived at http://orgprints.org/22557 
the potential indirect costs associated with compliance with stricter regulations) to be offset by an additional premium that consumers will be willing to pay for their products as a result of these being certified. It is also important to certifying bodies as they need to be able to demonstrate to producers that certification is worthwhile.

In Section 2, previous research on consumer attitudes to organic food especially with regards to issues of trust and certification is considered, focussing on attitudes of UK consumers in particular. In Section 3, the methodology is described, including sections on a qualitative study with focus group discussions and a quantitative study with a willingness to pay (WTP) experiment and a consumer survey. Section 4 presents results of each of these approaches and Section 5 draws them together and discusses them in relation to the previous research considered in Section 2. Of particular interest within the present study is the question of whether UK consumers recognise certification logos and whether they trust such logos sufficiently to be willing to pay more for products labelled with them than for products which claim to be organic without any certification logo. 


\section{Section 2: The UK market for organic foods and consumer trust in organic products and certification}

The UK market for organic foods is one of the largest in Europe after Germany and France although it suffered a decline during the recession and spend per person is considerably lower than in some other European countries (Willer and Kilcher, 2011). Sales of organic products in the UK in 2010 were worth $£ 1,731$ million which represented a decrease of $5.9 \%$ on the previous year and 86\% of households bought organic products in 2010 (Soil Association, 2011). Organic land in the UK decreased by 3\% in 2010 and makes up 4.2\% of UK farmland (DEFRA, 2011). Dairy products and fresh vegetables are the most popular categories of organic product in the UK representing 30.5\% and 23.2\% of total organic sales in 2010 (Soil Association, 2011). The most committed consumers (8\% of households buy organic products more than once a fortnight) are responsible for $54 \%$ of all organic sales in the UK (Soil Association, 2011). Most (approximately $75 \%$ ) organic food sales are made through three large supermarket chains, Tesco, Sainsbury and Waitrose (Wier et al., 2008), and most retailers have their own organic retail brands.

There have been several studies recently, both in the UK and in other countries, which have considered questions surrounding the topic of consumers and organic food consumption. These studies have contributed to a good understanding of, for instance, the profile of organic consumers (e.g. socio-demographic status) (Aertsens et al., 2009; Batte et al., 2007; Beaufort Research, 2010; Cottingham and Winkler, 2008; Hughner et al., 2007; Riefer and Hamm, 2011; Wier et al., 2008; Yiridoe et al., 2005), the reasons why consumers buy organic products (Aertsens et al., 2009; Beaufort Research, 2010; Condor, 2005; Cottingham and Winkler, 2008; Hughner et al., 2007; Pearson et al., 2011; Wier et al., 2008; Yiridoe et al., 2005; Zander et al., 2010), and their willingness to pay for organic food qualities. Also the barriers that nonconsumers acknowledge as reasons why they do not buy organic products have been well researched and, alongside price which is most commonly mentioned, a lack of trust is frequently mentioned (Hughner et al., 2007; Wier et al., 2008; Yiridoe et al., 2005). This lack of trust is one reason why certification logos are used and consumers' perceptions of the systems behind the logos have become important to the organic industry.

As a so-called credence good, organic food may be particularly susceptible to scepticism and lack of trust amongst consumers as they have no direct means of verifying that produce labelled as organic is indeed organic. Certification by an independent third-party may be one means of allaying such doubts among consumers but to be effective in doing so then consumers are required to trust the certification. Eden et al. (2008a), however, find that UK consumers in general do not trust third party assurance schemes (even those consumers who were members of the Soil Association) and suggest that labelling food and giving consumers more information

Archived at http://orgprints.org/22557 
about food will not necessarily lead to higher levels of trust and therefore purchase. Eden et al. (2008b) suggest that consumers in the UK support the principle of certification but are sceptical about the level of assurance it provides, i.e. how much checking is done and whether certifying bodies have enough power to enforce standards. The authors suggest that UK consumers are wary of being gullible, perhaps as a result of previous UK food scares. Similarly, Pettinger et al. (2004) find that the English are more likely than the French to agree that there are a lot of conflicting messages concerning healthy eating.

The issue of trust is also raised in discussions about local and organic produce. Several studies have indicated that consumers prefer locally grown organic produce to foreign organic goods (Yiridoe et al., 2005) and that they will even choose local conventional produce over organic produce (Batte et al., 2007; Beaufort Research, 2010; Cottingham and Winkler, 2008). Interestingly, it has been suggested by Clarke et al. (2008) and references therein that organic food is perceived as local and therefore produces a "trusting (re)connection between the anxious consumer and the responsive producer”. However, since a large proportion of organic produce sold in the UK is not grown in the UK (past estimates have suggested that $60 \%$ of produce sold is domestically produced (Green, 2004) implying that $40 \%$ is imported), the preference for local over organic food could become a barrier to purchase in the future, which should be an area of concern to organic producers. 


\section{Section 3: Methodology}

This study used qualitative and quantitative research techniques to gauge consumer reactions to organic certification logos: In a first step, an exploratory qualitative study with focus groups was carried out, followed by a quantitative study with choice experiments assessing WTP combined with a structured consumer survey. Each of these methods has advantages and disadvantages and by using a combination of methods it is possible to use them in a complementary fashion so as to mitigate the disadvantages of one method with the advantages of another.

The main reason for firstly conducting a qualitative study was that there had been little previous research on the specific topic of consumers and certification logos. A further quantitative study was then undertaken to measure statistically phenomena that had emerged from the qualitative study.

Qualitative research with focus groups allows a broader range of opinions to be revealed as participants interact with each other and react to the opinions of others but may have the disadvantage of resulting in participants giving what they believe to be socially acceptable answers and the risk that the discussion may be dominated by one or two individuals with strong opinions (thus careful facilitation is required) (Bryman, 2008). Focus group discussions are also inappropriate for sensitive topics where participants might feel uncomfortable talking in front of others, but this was deemed to be unlikely in the case of a discussion of organic certification.

The reason for combining choice experiments with a survey was that the survey would allow further analysis of factors that might influence the WTP which was measured in the choice experiments. Surveys reveal perceptions and beliefs which may have influenced consumption decisions. Using these three methods in combination allows them to complement each other and allows the researchers to identify areas where the three methods show good agreement. The individual methods are discussed in more detail below.

\section{Section 3.1 Qualitative study with focus group discussions}

Three focus group discussions were conducted in Reading in May 2009, each with nine or ten regular or occasional consumers of organic food, to obtain a first impression of their awareness and perception of organic certification and associated logos (see Figure 1). Participants were recruited by telephone by a market research institute which also provided the facilities. The room was a purpose built focus group laboratory with hanging microphones and a permanently installed video-camera. The sessions were facilitated by one of the authors of this paper. The participants were paid $£ 20$ in cash and consented to the research use of the data they provided in this study.

Archived at http://orgprints.org/22557 


\section{Take in Figure (1)}

The participants were selected to provide a reasonable spread over age and gender. Quota sampling was applied with the quotas for two age groups (18-44 and 45-75) reflecting the distribution of these age groups within the population. Regarding gender, the quotas were based on the buying behaviour within the population. The final breakdown of the groups is shown in Table 1. The participants had to be mainly or jointly responsible for the food purchase in their household and they had to be consumers of organic food.

Table 1: Composition of the focus group discussions

\begin{tabular}{|c|c|c|c|c|c|c|c|c|}
\hline \multirow[t]{2}{*}{ Groups } & \multicolumn{2}{|c|}{ Total } & \multicolumn{2}{|c|}{$\begin{array}{c}\text { Group } 1 \\
\text { (Occasional } \\
\text { consumers) }\end{array}$} & \multicolumn{2}{|c|}{$\begin{array}{c}\text { Group } 2 \\
\text { (Occasional } \\
\text { consumers) }\end{array}$} & \multicolumn{2}{|c|}{$\begin{array}{c}\text { Group } 3 \\
\text { (Regular } \\
\text { consumers) }\end{array}$} \\
\hline & $\mathrm{N}$ & $\%$ & $\mathrm{~N}$ & $\%$ & $\mathrm{~N}$ & $\%$ & $\mathrm{~N}$ & $\%$ \\
\hline Women, age $18-44$ & 9 & 31.0 & 3 & 30 & 3 & 30 & 3 & 33.3 \\
\hline Women, age 45-75 & 8 & 27.6 & 3 & 30 & 3 & 30 & 2 & 22.2 \\
\hline Men, age 18-44 & 6 & 20.7 & 2 & 20 & 2 & 20 & 2 & 22.2 \\
\hline Men, age 45-75 & 6 & 20.7 & 2 & 20 & 2 & 20 & 2 & 22.2 \\
\hline Total & 29 & 100 & 10 & 100 & 10 & 100 & 9 & 100 \\
\hline
\end{tabular}

The commitment of potential participants to buying organic food was assessed by asking how frequently they buy organic products in a range of seven different categories with the answers "almost never", "sometimes" and "almost always" scoring 0 , 1, and 2 respectively. Occasional and regular organic consumers were differentiated based on their answers: those scoring between 3 and 6 points were taken to be occasional consumers and those scoring more highly were regarded as regular organic consumers.

Regular consumers were separated from occasional consumers as there was a risk that during discussion they would be perceived as "experts" and the occasional consumers would defer to them or not express their own opinions as a result. The occasional consumers were split into two groups (see Table 1) to maintain focus group sizes of approximately ten participants.

Participants were asked to consider questions such as, "How do you recognise organic food when you go shopping?”, "Why do you look for particular words, labels or symbols?”, “Do you prefer products with one of these labels (Soil Association logo, Organic Farmers and Growers (OF\&G) logo, Organic Food Federation logo, EU logo, no logo - just the word “organic”)?”, "Are you aware of any differences in organic standards behind these labels?”, "Do you think that 
there are price differences between products that are labelled with the different logos?”. The selection of logos was based on a preliminary inventory of the presence of logos on products in UK shops in November 2008.

The data from the focus groups were analysed in two stages following the format of qualitative content analysis described by Janssen and Hamm (2011a). Initially the data was analysed to give an overview of the discussion and to identify themes which ran through the focus groups. In the second stage, identified themes and subthemes were used to categorise the comments made and a further "other" category was used to identify additional comments which may be of interest in the research.

\section{Section 3.2 Quantitative study with consumer choice experiments and surveys}

Participants were recruited on-the-spot at the locations of the WTP experiment/survey (discussed below). They had to be mainly or jointly responsible for buying food in their household. Only consumers who stated that they buy organic eggs and apples at least once or twice per month were asked to participate in the choice experiments and survey. The selection criterion regarding organic food consumption used for the choice experiments was different to the one used for the focus groups, since it needed to ensure that the results reflect the preferences of consumers who actually buy the two test products in organic quality.

$70 \%$ of the participants were female, reflecting the distribution of main food shoppers in the population, and sampling quotas ensured an even spread across two age groups: $52 \%$ in the 18 to 44 years age bracket and $48 \%$ in the 45 to 75 years age bracket. In total 410 consumers were interviewed.

Data were collected at two kinds of shops/locations in the UK: conventional supermarkets (three locations used - Newbury, Reading, Wantage) and specialised organic food shops (one location used - Bristol). The proportion of interviews conducted in each location reflected the organic market share of that kind of shop in the UK grocery market $(74.7 \%$ for conventional supermarkets and $25.3 \%$ for specialised organic food shops). The choice experiment and interview took between 12 and 20 minutes per participant and the data were collected by some of the authors of this paper and their colleagues. The choice experiments/surveys were carried out in February and March 2010. The participants were paid $£ 10$ in cash and consented to the research use of the data they provided in this study.

\subsubsection{Experimental setup of the choice experiments}

In the choice experiments, each participant was presented with two sets of organic apples and two sets of organic eggs. Apples and eggs were chosen for the products for the choice experiments as it was intended to investigate both a plant and an animal product and many

Archived at http://orgprints.org/22557 
consumers regularly buy apples and eggs. Also, organic apples and eggs are readily available and it is easier to guarantee a uniformity of appearance in apples and eggs than other products (e.g. meat) and so appearance was likely to have a minimal impact in the choice experiments.

The apples and eggs were selected to look identical but were labelled differently, with four different prices (Table 2) and four different organic labels (Label $1=$ EU logo, Label 2 = Soil Association logo, Label 3 = OF\&G logo, Label 4 = no logo). The selection of logos was based on the results of an inventory study and focus group results. The participants were also allowed to select a "no buy" option which indicated that they would not be willing to purchase any of the alternatives offered.

One month before the experiment, typical market prices for apples and eggs in the region where the choice experiments were checked in several shops. The four tested price levels equalled $80 \%$, $100 \%, 120 \%$ and $140 \%$ of the average market price respectively (Table 2). In the sample, the price levels varied systematically across the four logos. The experimental design for the systematic variation of the price levels across the four product alternatives was based on a fractional factorial design with 16 different choice sets developed with the software SPSS. The participants were presented with two choice sets for apples and eggs respectively, i.e. in total each participant made four buying decisions.

Table 2: Prices in the experiments

\begin{tabular}{|c|c|c|}
\hline $\begin{array}{c}\text { \% of average } \\
\text { market price }\end{array}$ & Apples & Eggs \\
\hline $80 \%$ & $£ 1.98$ & $£ 1.72$ \\
\hline $100 \%$ & $£ 2.48$ & $£ 2.12$ \\
\hline $120 \%$ & $£ 2.98$ & $£ 2.58$ \\
\hline $140 \%$ & $£ 3.48$ & $£ 2.98$ \\
\hline
\end{tabular}

\subsubsection{Analysis of WTP}

As described above, the consumers were asked to choose among five alternatives (four product alternatives plus a "no-buy" option). In the model, the dependent variable is "choice" which is a discrete nominal variable. As discussed by Louviere et al. (2000), discrete choice analysis is based on Random Utility Theory which postulates that an individual who makes a choice among a set of different alternatives acts rationally and attempts to choose the product which they perceive as having the highest utility.

Archived at http://orgprints.org/22557 
In basic choice models, the utility of choosing alternative $i$ out of a choice set of $J$ alternatives is composed of the observed utility $V_{i}$ and the stochastic element $\varepsilon_{i}$ which captures the unobserved utility.

Based on the hypothesis of random utility maximisation discussed above, it is possible to estimate the probability (Prob) that alternative $i$ is chosen out of a choice set of $J$ alternatives in a multinomial logit model:

$$
\operatorname{Prob}_{i}=\frac{\exp V_{i}}{\sum_{j}^{J} \exp V_{j}}
$$

The observed utility depends on the product attributes controlled in the experiment $x_{k}$ (in this case the price) with the associated $\beta_{k}$ coefficients and an alternative specific constant $\left(A S C_{i}\right)$ (in this case the logo is represented by this constant as the logos did not vary across the experiment every logo is present in every choice set). It is not possible to estimate a model with an ASC in every utility function but only in $J-1$ utility functions (to avoid multicollinearity) thus the utility function for the label with no logo, just the word "organic" does not contain an ASC. In these choice experiments price is the only attribute that was varied. Thus the equations that summarise the utilities can be written as below:

$$
\begin{aligned}
& U_{\text {label1 } 1}=V_{\text {label1 } 1}+\varepsilon_{\text {label1 }}=A S C_{\text {label1 }}+\beta_{\text {PRICE }} P R I C E+\varepsilon_{\text {label1 }} \\
& U_{\text {label } 2}=V_{\text {label } 2}+\varepsilon_{\text {label } 2}=A S C_{\text {label } 2}+\beta_{\text {PRICE }} \text { PRICE }+\varepsilon_{\text {label } 2} \\
& U_{\text {label3 }}=V_{\text {label3 }}+\varepsilon_{\text {label3 }}=A S C_{\text {label3 }}+\beta_{\text {PRICE }} \text { PRICE }+\varepsilon_{\text {label3 }} \\
& U_{\text {label } 4}=V_{\text {label } 4}+\varepsilon_{\text {label } 4}=\beta_{\text {PRICE }} \text { PRICE }+\varepsilon_{\text {label } 4} \\
& U_{N o-b u y}=V_{N o-b u y}+\varepsilon_{N o-b u y}=A S C_{N o-b u y}+\varepsilon_{N o-b u y}
\end{aligned}
$$

The model provides estimates for the coefficient of the PRICE parameter and ASCs.

Using logit models allows the WTP for a specific product attribute to be determined if the model contains a price-related parameter. Thus,

$$
W T P_{i}=-\frac{A S C_{i}}{\beta_{P R I C E}}
$$

This measure provides the additional WTP for apple/eggs with a specific logo compared to organic apples/eggs without a logo, since in the above utility function the ASCs were defined in relation to the alternative without a logo (label 4).

\section{Section 3.2.3 Consumer survey}


The survey followed on from the choice experiments which are described above in Section 3.2.1 The aim was to assess consumer awareness and perception of different certification schemes and corresponding logos. The survey referred to the logos of the Soil Association and OF\&G, the old (i.e pre-July 2010 voluntary logo) EU logo and a label with the word “organic” but no logo.

Consumers selected for the survey were asked to fill in a short questionnaire that examined their perception and expectations of organic standards and logos. They were asked to state their opinion of each of the four labels including what they thought of the underlying standards and inspection systems. Participants were asked to rank each label on a scale of 1 to 7 for the statements listed below with 1 indicating strong disagreement (or a belief that standard/inspection are "below average") and 7 indicating strong agreement (or a belief that standard/inspection are "above average") i.e. 1 is associated with strongly negative perceptions with regards to the label and 7 with strongly positive perceptions with regards to the label. In addition, the participants could answer "I don't know".

The statements which were given included:

- This label is well known to me

- I do trust this label

- This label does stand for an organic product

- What do you think? How strict are the organic standards behind the label? (1=below average, $4=$ average, $7=$ above average)

- What do you think? How strict is the inspection system behind the label? (1=below average, $4=$ average, $7=$ above average)

Then they were asked about their preferred places to purchase organic food and their organic budget share. They were also asked about socio-demographic data such as gender, age, household size, level of education and net household income which in previous research have been found to influence organic consumer behaviour. 


\section{Section 4: Results}

The results of the qualitative and quantitative methods used in this study are presented separately in this section. These results will then be combined and discussed in relation to previous research in Section 5.

\section{Section 4.1 Focus groups}

The main themes that were identified in the analysis were: consumer awareness and perception of organic certification logos and production standards associated with logos, consumer preference for any of the logos and reasons why particular logos were preferred/not preferred.

The initial discussion focussed on how the participants identified organic products when shopping. Many of them looked for the word "organic" on products, for own-branded organic goods or for specific organic sections in supermarkets. Some participants mentioned shopping at organic stores and farmers markets or belonging to vegetable box schemes, and suggested that these channels gave them more confidence in the organic authenticity of the products. Indeed, this issue of trust in the authenticity of organic products was raised in all three focus groups and most participants were unaware that there was a certification system (even in the regular consumers group). Only one of the 29 participants of all three groups spontaneously mentioned the Soil Association logo as part of this discussion. This lack of knowledge seemed to have added to the lack of trust in the industry. The higher price of organic food was also mentioned very early on in the discussions as some participants said that if they noted a product was expensive then they would look at it in more detail to determine whether it was organic.

The participants were then shown a selection of logos and were asked about recognition (Figure 1). The majority of participants did not recognise any of the certification logos. A few recognised the Soil Association logo, and some expressed a preference for products with this logo. Some thought that they recognised the OF\&G logo but did not have a clear preference for it. The majority of the participants did not recognise the EU logo (this was the old logo, now phased out) although some participants identified it by recognising the stars and guessing that this was EU related. All of the participants were unaware of any differences in organic standards behind the logos and it became apparent throughout the focus group discussions that most participants had very limited knowledge of organic agriculture, organic standards and certification. Several of the participants reiterated statements which showed that they were very sceptical about the authenticity of organic produce. For example:

"I think my problem is (...) do you believe if you're a bit sceptical? You think is it really organic?' That's one of my issues, is all of this genuine? Is it really organic?” Focus group 2, female.

Archived at http://orgprints.org/22557 
These participants were under the impression that the industry was not regulated and that anyone could label their product "organic". There was also a level of cynicism shown by the participants with several of them feeling that organic was a marketing tool.

\section{Section 4.2 WTP models}

Table 3 shows the parameter estimates of the MNL models, based on which the WTP measures were determined (the "no buy" cases where participants stated that they did not like the look/smell of any product or that they only bought from one specific shop were excluded). Both MNL models are statistically significant at the 99.99\% level (using a Chi square test) and meet the independence of irrelevant alternatives (IIA) assumption required by MNL models (Louviere et al., 2000). The IIA assumption was checked with the Hausman-test as described by Hensher et al. (2005) (the Hausman-test showed p-values of greater than 0.78 suggesting that the IIA assumption cannot be rejected).

The egg model has a higher Log Likelihood function compared with the apple model suggesting a slightly better fit to the data. One explanation of this could be that the eggs would have been more uniform in appearance than the apples and so the look of the apples, rather than the labels, could have influenced some choices.

It can be seen from Table 3 that the preference for a product decreases the higher its price. Whether or not the ASC is positive indicates whether the preference for a product increases, or decreases based on the product attribute. The presence of the Soil Association logo or the OF\&G logo increases the preference for a product. These results are significant at the $\mathrm{P}<0.001$ threshold. In contrast, while the ASC for the EU logo in the apple model is positive, indicating that its presence may increase preference for a product, this is not significant for the egg model and is only significant at the $\mathrm{P}<0.1$ level for the apple model.

Table 3: Results of the MNL models

\begin{tabular}{|l|c|c|c|c|c|}
\hline & \multicolumn{2}{|c|}{ Apple model (n=395) } & & \multicolumn{2}{c|}{ Egg model (n=393) } \\
\hline & Coefficient & Std. error & & Coefficient & Std. error \\
\hline Price & $-0.940^{* * *}$ & 0.077 & & $-1.290^{* * *}$ & 0.962 \\
\hline ASC EU logo & $0.228^{*}$ & 0.132 & & 0.210 & 0.150 \\
\hline ASC Soil Association logo & $0.950^{* * *}$ & 0.118 & & $1.262^{* * *}$ & 0.130 \\
\hline ASC OF\&G logo & $1.017 * * *$ & 0.117 & & $1.432^{* * *}$ & 0.128 \\
\hline ASC No-buy & $-7.140^{* * *}$ & 1.022 & & $-5.522^{* * *}$ & 0.465 \\
\hline Log Likelihood function & \multicolumn{2}{|c|}{-962.57} & & \multicolumn{2}{c|}{-909.90} \\
\hline
\end{tabular}

*** $\mathrm{P}<0.001,{ }^{* *} \mathrm{P}<0.01,{ }^{*} \mathrm{P}<0.1$.

Archived at http://orgprints.org/22557 
Table 4 shows the WTP for each of the logos and its associated statistical significance. The WTP is given in pounds sterling as the results were carried out in the UK and relate to UK certification logos. It can be seen from Table 4 that the results for the EU logo are insignificant for the eggs model and have very low significance for the apples model.

Table 4: Additional WTP (above what would be paid for a label with no logo) for the three organic logos considered in this project in $£$ sterling.

\begin{tabular}{|l|l|l|}
\hline & Apples (N=395) & \multicolumn{1}{c|}{ Eggs (N=393) } \\
\hline & WTP & WTP \\
\hline EU logo & $0.24^{*}$ & not significant \\
\hline Soil Assn. logo & $1.01^{* * *}$ & $0.98^{* * *}$ \\
\hline OF\&G logo & $1.08^{* * *}$ & $1.12^{* * *}$ \\
\hline
\end{tabular}

*** $\mathrm{P}<0.001, * * \mathrm{P}<0.01, * \mathrm{P}<0.1$.

It should be noted that MNL models can tend to over-estimate WTP and so the results are best viewed in relation to each other, rather than as absolutes. The table shows that the Soil Association and OF\&G logos create a greater willingness to pay than the EU logo which attracts a minimal (for apples), or statistically insignificant (for eggs), premium compared with no logo.

\section{Section 4.3 Consumer survey}

Table 5 summarises the results, showing the share of participants who gave a very positive perception of the label (i.e. score of 6 or 7 on the seven-point Likert scale), and Figure 2 presents these in graphical form. This shows some difference in consumer perceptions of the different certification logos (see Table 5 and Figure 2). In relation to most questions the Soil Association received the highest ratings, mostly followed by the OF\&G logo. Only in response to the statement, 'This logo is well known to me' did the no-logo option come second. It can be seen from these results that recognition of the logos was much higher in this group of consumers than it had been for the focus group participants.

Table 5: Consumer awareness and perception of different labels.

\begin{tabular}{|l|c|c|c|c|}
\hline & $\begin{array}{c}\text { Label 1 } \\
- \text { EU }\end{array}$ & $\begin{array}{c}\text { Label 2 } \\
\text { - SA }\end{array}$ & $\begin{array}{c}\text { Label 3 - } \\
\text { OF\&G }\end{array}$ & $\begin{array}{c}\text { Label 4 - } \\
\text { no logo }\end{array}$ \\
\hline $\begin{array}{l}\text { Awareness: Share of participants who stated to know the } \\
\text { label well }\end{array}$ & $3 \%$ & $70 \%$ & $40 \%$ & $68 \%$ \\
\hline Trust: Share of participants who stated to trust the label & $14 \%$ & $75 \%$ & $59 \%$ & $29 \%$ \\
\hline $\begin{array}{l}\text { Credibility: Share of participants who believed that the } \\
\text { label stood for organic products }\end{array}$ & $22 \%$ & $78 \%$ & $67 \%$ & $27 \%$ \\
\hline $\begin{array}{l}\text { Standards: Share of participants who perceived the } \\
\text { underlying standards to be above average }\end{array}$ & $14 \%$ & $71 \%$ & $56 \%$ & $10 \%$ \\
\hline
\end{tabular}




\section{Take in Figure (2)}

The percentage of participants answering “I don’t know” for each question is shown in Table 6 . It can be seen from this that the greatest level of confusion surrounded the EU logo which received the largest number of “don't know” responses to each question, emphasising that it was not well known to consumers. It can also be seen from this table that consumers were generally unsure of the level of standards and inspection underlying the Soil Association and OF\&G logos and even more unsure of the levels of standards and inspection required for a product to be labelled “organic” with no certification logo.

Table 6: The percentage of "I don't know" answers for each label and rating question

\begin{tabular}{|l|c|c|c|c|}
\hline & Label 1 - EU & Label 2 - SA & Label 3 - OF\&G & Label 4 - no logo \\
\hline Trust & $34 \%$ & $6 \%$ & $7 \%$ & $10 \%$ \\
\hline Credibility & $37 \%$ & $6 \%$ & $9 \%$ & $16 \%$ \\
\hline Standards & $49 \%$ & $10 \%$ & $18 \%$ & $26 \%$ \\
\hline Inspection system & $54 \%$ & $15 \%$ & $27 \%$ & $36 \%$ \\
\hline
\end{tabular}

The participants were then asked whether they thought any of the logos indicated national provenance of the product. Approximately $54 \%$ of participants thought that the OF\&G logo represents a British product (Figure 3) although in reality this is not always the case. Participants' comments indicated that many consumers thought that the OF\&G logo stands for a co-operative group of UK-based organic farmers. A surprisingly large number of participants (almost 40\%) also thought that the Soil Association logo indicated British origin.

\section{Take in Figure (3)}




\section{Section 5 Discussion and Conclusions}

The combined results of the three methods used in this study suggest that UK consumers have concerns over the authenticity of organic food and are not fully aware of the certification and inspection process, but do have some trust in the Soil Association and OF\&G logos and so are willing to pay a premium for products labelled with these.

During the focus group discussions there was only limited awareness and recognition of organic certification logos. This is likely to be related to the fact that in the UK many organic products are sold as private brands of retailers with the certification logos not shown very prominently on product packages. The Soil Association logo was the most recognised and the EU logo the least. Most consumers were unaware that there was a certification system for organic produce with many commenting on issues of trust and authenticity.

The generally higher recognition of the Soil Association logo in the focus groups carried through into the consumer survey and WTP experiments where the participants appeared to be more frequent organic consumers and were more familiar with the logos in general. The Soil Association logo was the most highly rated across all the questions followed by the OF\&G logo. Although the word "organic" triggered a similar level of recognition, it fell below these two logos in areas such as trust and the level of standards it was perceived to represent. There appeared to be an erroneous perception amongst the majority of participants that the OF\&G logo indicates British origin and more than a third of consumers surveyed also thought that the Soil Association logo represented British origin. The WTP experiments tested whether the consumers were willing to pay a premium for any of the logos and the survey attempted to find explanations for the behaviour observed in these choice experiments. In this case, the experiment appeared to show a generally good agreement with the survey results as UK consumers showed a WTP a significant premium for products labelled with the Soil Association or OF\&G logos as compared with products simply marked with the word "organic". These were also the labels which they appeared to be most aware of in the survey and that were rated most highly in terms of trust and the perception that the underlying standards were high and inspection processes were strict.

The consumers participating in the focus groups in particular showed a lack of awareness of certification logos and a more general lack of knowledge of the meaning of "organic", the organic industry and how it is regulated including the fact that certification was available. Even the participants in the choice experiments/surveys, who showed a greater familiarity with the logos, were still unsure about certification standards and the inspection process. During the focus group discussions participants also expressed a lack of trust in organic products and doubts as to the authenticity of products which claim to be organic. This scepticism is similar to that reported by Eden et al. (2008a) who found that UK consumers were sceptical about claims regarding food

Archived at http://orgprints.org/22557 
and did not per se trust third party assurance schemes. Consumer scepticism is a great challenge for the UK organic industry as consumers are unlikely to pay more for a product if they do not feel that they can trust that it really is organic.

It is promising for the industry, however, to note that both the Soil Association and OF\&G logos (of the labels tested in the study - no logo, EU logo, Soil Association logo and OF\&G logo) were able to attract a significant premium over products simply marked "organic" suggesting that once consumers recognise and trust a certification logo, they are willing to pay a premium for the additional level of assurance that they perceive it provides. This is despite the results of Eden et al. (2008a) who found that even some members of the Soil Association expressed doubts about third party assurance.

In conclusion, UK consumers are slightly sceptical about organic products and unsure about certification. Eden et al. (2008b) suggest that UK consumers are wary of being gullible, perhaps as a result of previous food scares in the UK, while Pettinger et al. (2004) suggest that the English feel that there are many conflicting messages about healthy eating. It is possible that this combination of a fear of being gullible and a feeling of information overload leads to the high levels of scepticism shown in UK consumers. UK consumers are also unsure about the standards and inspection processes which lie behind the certification logos shown on organic foods. The fact that they are willing to pay a premium for some certification logos suggests that they do value the assurance these bring once they are sufficiently aware of them. It thus seems promising for any certification scheme to invest in consumer communication for raising awareness of their logo and the control system standing behind it.

These results suggest that organic producers can view certification as a means of increasing the amount that consumers are willing to pay for their produce and so may wish to consider displaying the logos clearly on packaging where they have the ability to choose to do so. The results also suggest that certifying bodies need to ensure that consumers are aware of their logos and the standards and inspection processes which producers must comply with to merit certification.

The results also imply that the new EU logo (the logo which became mandatory in July 2010) will require to become known to UK consumers as they are likely to view it with a degree of scepticism and mistrust initially (Janssen and Hamm, in press).

Further research on these topics could include a comparison of willingness to pay for organic certification logos with other logos which may represent some of the benefits which consumers perceive as coming from organic produce e.g. the LEAF (linked environment and farming) logo which gives consumers information about the environmental/biodiversity benefits of products and the "Freedom Foods" logo of the Royal Society for the Protection of Animals (RSPCA) which gives consumers information about animal welfare standards. It would be interesting to

Archived at http: //orgprints.org/22557 
see whether, as previous research has suggested that these benevolent reasons for buying organic food are secondary to ego-centric reasons, organic logos can command a higher premium than these kinds of logos. It would also be interesting to compare willingness to pay for organic food with willingness to pay for local food and for food which is both local and organic as recent research (Batte et al., 2007; Brown et al., 2009; Cottingham and Winkler, 2008; Smithers et al., 2008) has also highlighted the importance of local food to consumers (although it is worth noting that definitions of local can vary). Once the mandatory EU logo has been in place for some time it would also be useful to repeat the research carried out in this study but with the new logo to see whether awareness and trust of this logo is higher than for the previous, voluntary logo, and whether as a result it can obtain a similar premium to the logos of UK certification bodies.

Finally, it should be noted that this study has only considered the opinions of consumers who already buy some organic produce and was based in the South of England. It is known that there is a clear geographical split in the UK with regards to purchase of organic food, with households in London and the south of England more likely to purchase organic products than those in Scotland and the north of England (Wier et al., 2008), it would therefore be interesting to repeat this study in Scotland or the north of England to see whether consumers are as willing to pay a premium for products labelled with organic certification logos, especially as incomes are generally lower in these parts of the country.

\section{Acknowledgements}

This publication was generated as part of the CERTCOST project agreement no. 207727 (http://www.certcost.org), with financial support from the European Community under the $7^{\text {th }}$ Framework Programme. The publication reflects the views of the authors not those of the European Community, who is not to be held liable for any use that may be made of the information contained. The authors gratefully acknowledge funding from the European Community. The authors would like to thank Louisa Winkler for proof-reading. The authors would also like to thank the three anonymous reviewers for their helpful comments on this paper.

Archived at http://orgprints.org/22557 


\section{References}

Aertsens, J., Verbeke, W., Mondelaers, K. and Van Huylenbroeck, G. (2009) Personal determinants of organic food consumption: a review. British Food Journal, 10 1140-1167.

Batte, M. T., Hooker, N. H., Haab, T. C. and Beaverson, J. (2007) Putting their money where their mouths are: consumer willingness to pay for multi-ingredient processed organic food products. Food Policy, 32 145-159.

Beaufort Research (2010) Consumer attitudes towards organic food - phase 2: survey of general public, BOBL.

Brown, E., Dury, S. and Holdsworth, C. (2009) Motivations of consumers that use local, organic fruit and vegetable box schemes in Central England and Southern France. Appetite, 53 183-188.

Bryman, A. (2008) Social research methods, 3rd edition. Oxford: Oxford University Press.

Clarke, N., Cloke, P., Barnett, C. and Malpass, A. (2008) The spaces and ethics of organic food. Journal of Rural Studies, 24 219-230.

Condor (2005) Consumer decision making on organic products, EU project number OLK1-2002-02446.

Cottingham, M. and Winkler, E. (2008) The Organic Consumer. In: Wright, S. and Mccrea, D. eds. The handbook of organic and fair trade food marketing. Wiley, pp. 29-53.

DEFRA (2011) Organic statistics 2010 United Kingdom. National statistics release published on 11 August 2011. Department for Environment Food and Rural Affairs, London.

Eden, S., Bear, C. and Walker, G. (2008a) The sceptical consumer? Exploring views about food assurance. Food Policy, 33 624-630.

Eden, S., Bear, C. and Walker, G. (2008b) Understanding and (dis)trusting food assurance schemes: consumer confidence and the "knowledge fix". Journal of Rural Studies, 24 1-14.

Green, M. (2004) Organic Food and Farming Report 2004. Soil Association.

Hensher, D. A., Rose, J. M. and Greene, W. H. (2005) Applied choice analysis: A primer. Cambridge: Cambridge University Press.

Hughner, R. S., McDonagh, P., Prothero, A., Schultz, C. J. and Stanton, J. (2007) Who are organic food consumers? A compilation and review of why people purchase organic food. Journal of Consumer Behaviour, 6 94-110.

Janssen, M. and Hamm, U. (2011a) Consumer perception of different organic certification schemes in five European countries. Organic Agriculture, 1 (1), 31-43.

Janssen, M. and Hamm, U. (2011b) Consumer preferences and willingness-to-pay for organic certification logos, report of WP3 of CERTCOST project.

Janssen, M. and Hamm, U. (in press) The mandatory EU logo for organic food: Consumer perceptions. British Food Journal, 114 (3),

Louviere, J. J., Hensher, D. A. and Swait, J. D. (2000) Stated choice methods, analysis and applications. UK: Cambridge University Press.

Organic Rules (2011) http://organicrules.org/custom/countrystandard.php?id=168. [Accessed 25.7.2011].

Pearson, D., Henryks, J. and Jones, H. (2011) Organic Food: what we know (and do not know) about consumers. Renewable Agriculture and Food Systems, in press

Pettinger, C., Holdsworth, C. and Gerber, M. (2004) Psycho-social influences on food choice in Southern France and Central England. Appetite, 42 307-316.

Archived at http://orgprints.org/22557 
Smithers, J., Lamarche, J. and Joseph, A. E. (2008) Unpacking the terms of engagement with local food at the Farmers' Market: Insights from Ontario. Journal of Rural Studies, 24 337-350.

Soil Association (2011) Organic market report 2011. Bristol.

Wier, M., O'Doherty Jensen, K., Andersen, L. M. and Millock, K. (2008) The character of demand in mature organic food markets: Great Britain and Denmark compared. Food Policy, 33 406-421.

Willer, H. and Kilcher, L. (2011) The World of Organic Agriculture: Statistics and Emerging Trends 2011. FiBL and IFOAM.

Yiridoe, E. K., Bonti-Ankomah, S. and Martin, R. C. (2005) Comparison of consumer perceptions and preference toward organic versus conventionally produced foods: A review and update of the literature. Renewable Agriculture and Food Systems, 20 (4), 193-205.

Zander, K., Hamm, U., Freyer, B., Gossinger, K., Hametter, M., Naspetti, S., Padel, S., Stolz, H., Stolze, M. and Zanoli, R. (2010) Farmer Consumer Partnerships - How to successfully communicate the values of organic food. 